\title{
Oestrogen and progestogen receptor content in human endometrium
}

\author{
M. Snijders ${ }^{\mathrm{a}, *}$, A. de Goeij ${ }^{\mathrm{b}}$, J. Koudstaal ${ }^{\mathrm{c}}$, F. Bosman ${ }^{\mathrm{d}}$ \\ a Deptartment of Gynaecology and Obstetrics, St Maartens Hospital, P.O. Box 1926, 5900 BX Venlo, Netherlands \\ ${ }^{\mathrm{b}}$ Department of Pathology, Academic Hospital Maastricht, Maastricht, Netherlands \\ 'Department of Pathology, De Wever Hospital Heerlen, Heerlen, Netherlands \\ ${ }^{\mathrm{d} D e p a r t m e n t}$ of Pathology, Academic Hospital Rotterdam, Rotterdam, Netherlands
}

\section{Introduction}

The cyclic process of proliferation, secretory differentiation, (pre)decidualization, menstrual degeneration and regeneration in premenopausal endometrium is controlled by oestrogens and progestogens, and is mediated through binding to their specific receptors. Oestrogen (ER) and progestogen receptor (PR) presence and concentration indicate not only hormonal influence on the specific cells but also the capacity to respond to these hormones.

$E R$ and $P R$ concentrations in endometrium vary with the phases of the menstrual cycle, but their relationship to cyclic changes in histomorphology and hormonally modulated tissue factors in the specific cell types has not been extensively studied. There is some evidence that these changes reflect functional processes resulting, at least in part, from interactions between the different endometrial cell types [1].

\section{Aim of the study}

To investigate the cell-type specific endometrial responses to cyclic oestrogen and progestogen stimulation by analysing steroid receptor expression and comparing it with the cyclic changes in histomorphology and functional activities during the different phases of the menstrual cycle.

\section{Materials and methods}

Distribution and intensity of immunocytochemical ER and PR staining were semiquantitatively scored in the various cell types of the midfundus endometrium functionalis and basalis of 30 normal premenopausal uteri by the use of paraffin-embedded sections. The results were statistically analysed for the different phases of the menstrual cycle $(\mathrm{I}=$ menstruation, $\mathrm{II}=$ early proliferative, III = late proliferative, IV = early secretory, $\mathrm{V}=$ midsecretory or VI late secretory).

\section{Results}

During the menstrual cycle (Fig. 1), statistically significant changes in ER score were observed in the glandular and stromal cells of endometrium basalis and functionalis. In all cell types ER expression reached a maximum in the late proliferative phase (III) (Fig. 2a). During the early secretory phase (IV), ER staining declined sharply in the stromal cells, whereas, in glandular cells ER expression decreased more gradually. During the mid (V) and late secretory (VI) phases an increase in ER staining was observed in predecidualizing stromal cells.

PR numbers changed significantly in glandular epithelium but not in the stromal cells. Glandular PR expression reached a maximum in the early secretory phase (IV) and was then drastically reduced. During mid (V) and late secretory (VI) phases stromal cells were moderately stained for PR in contrast to epithelial gland cells which showed no or very weak staining (Fig. 2b).

\footnotetext{
* Corresponding author.
} 

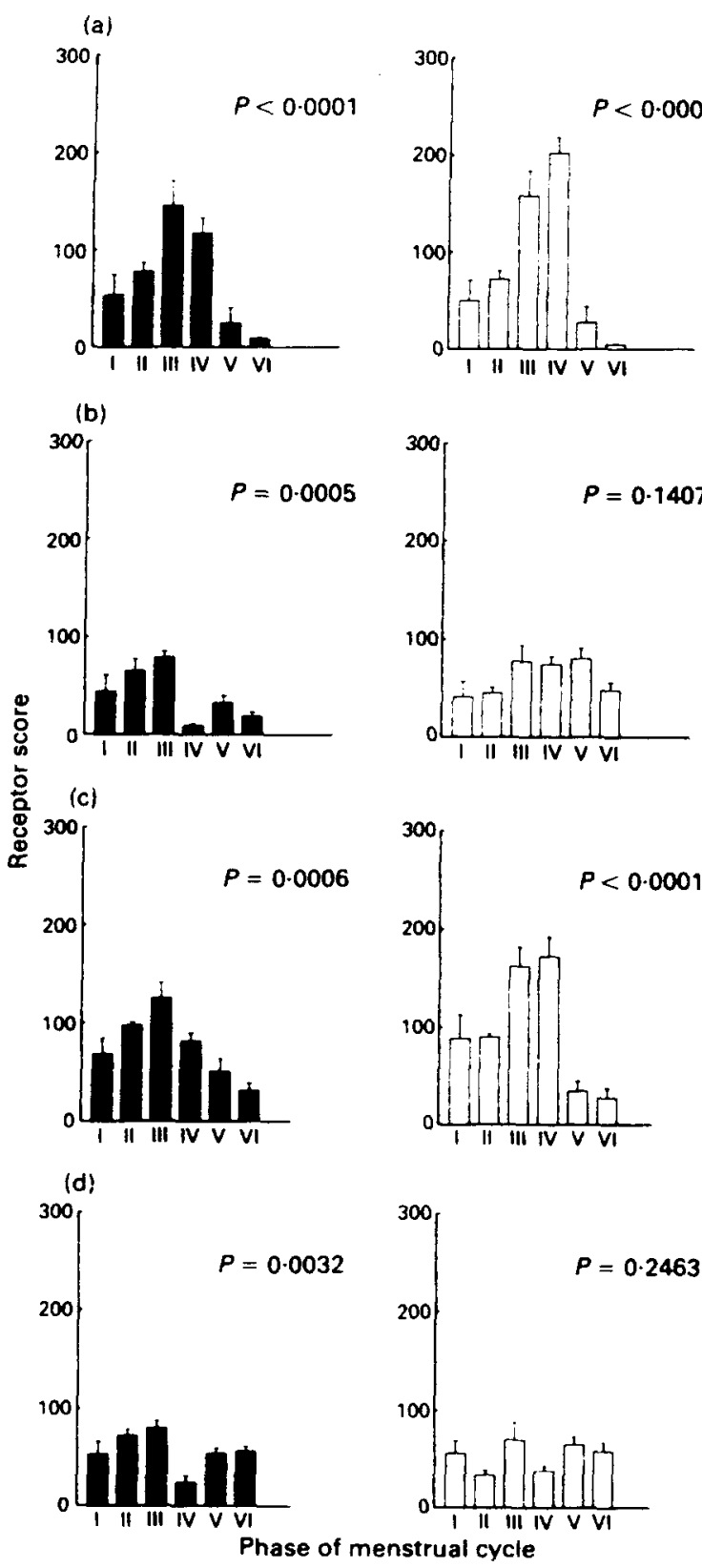

Fig. 1. Immunocytochemical oestrogen receptor (closed bars) and progesterone receptor (open bars) scores (mean \pm S.E.M., $n=5$ ) in (a) glandular epithelium functionalis, (b) stroma functionalis, (c) glandular epithelium basalis, and (d) stroma basalis during menstrual cycle phases I-VI.

\section{Conclusions}

During the secretory phases of the menstrual cycle the stroma shows a 'dyssynchronized' $E R$ and PR
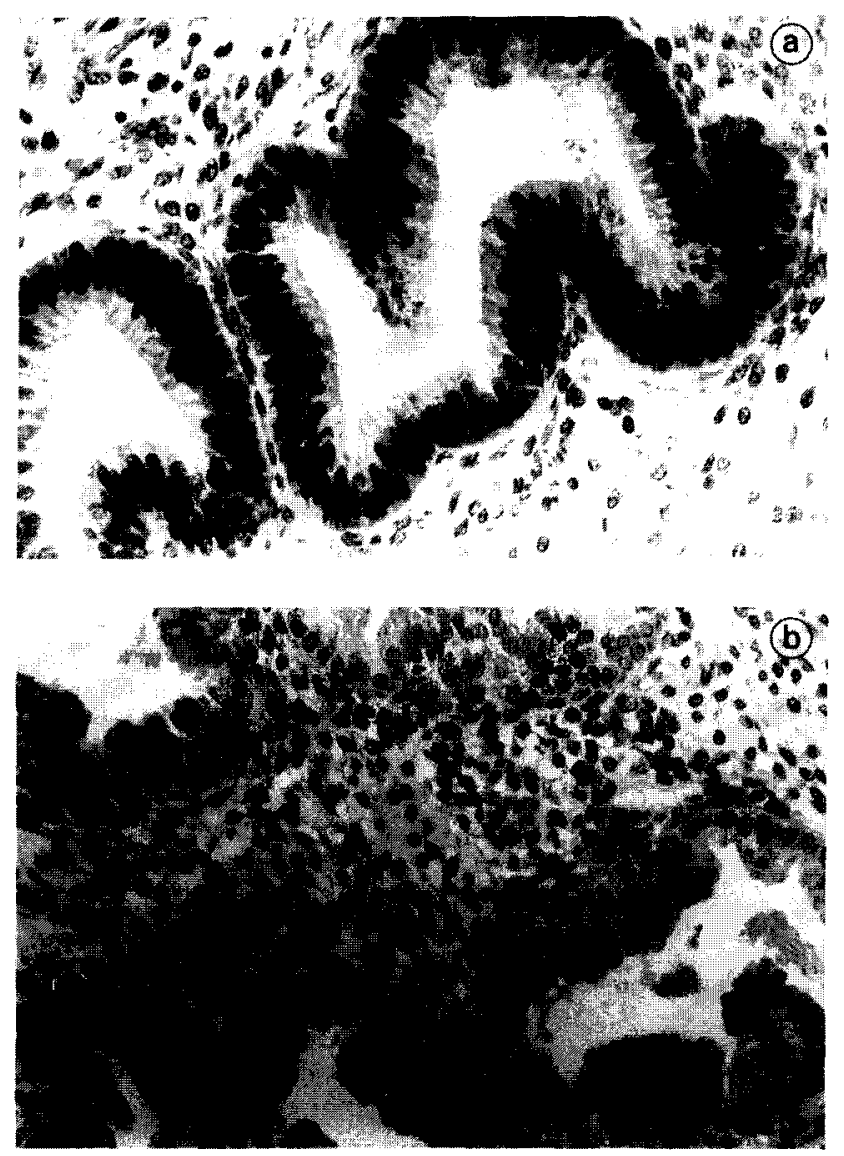

Fig. 2. Immunostaining of steroid receptors.

immunoreactivity-pattern when compared with the adjacent glandular epithelium. The reappearance of ER and the persistence of PR during the secretory phases suggest autocrine regulation of the stroma functionalis as an implantation layer for the fertilized ovum. Maximum secretion by the glandular epithelial cells in absence of PR immunoreactivity suggests a paracrine link between the (pre)decidualizing stroma and the glandular epithelium.

This study shows that the endometrial response or responsiveness to cyclic hormonal stimulation is indeed cell-type specific, and therefore a differential steroid metabolism according to cell type is strongly suggested.

\section{References}

[1] Snijders $M$ et al. Immunocytochemical analysis of oestrogen and progesterone receptors in the normal human uterus throughout the menstrual cycle and after menopause. J Reprod Fertil 1992; 94: $361-369$. 